Jie Cai*, Qingfeng Guan, Peng Lv, Conglin Zhang and Yunxiao Yin

\title{
Crater Formation on the Surface of Pure Metal and Alloy Irradiated by High Current Pulsed Electron Beam
}

https://doi.org/10.1515/htmp-2017-0067

Received May 10, 2017; accepted October 9, 2017

\begin{abstract}
A detailed investigation concerning the formation mechanism of craters of pure metal and alloy surface after high-current pulsed electron beam (HCPEB) processing has been carried out. After HCPEB irradiation, typical craters were homogeneously distributed on the entire surface of $3 \mathrm{Cr} 13$ stainless steel, resulting from local sublayer melting and eruption through the solid outer surface. Comparatively, almost no craters were created of pure zirconium, which was associated with the shallow melting site and incomplete treated surface. Furthermore, a large number of ultrafine grains were formed on the irradiated surface, indicating that surface melting was the dominant interaction mechanism between HCPEB irradiation and pure zirconium. It is apparent that "crater free" phenomenon plays a dominant role in surface modification of zirconium and zirconium alloys.
\end{abstract}

Keywords: high-current pulsed electron beam (HCPEB), 3Cr13 stainless steel, pure zirconium, crater formation

\section{Introduction}

Recently, the application of energetic beams such as ion [1], electron [1-3] and laser [4] has been applied to modify the surface of metallic materials. Among these pulsed beam techniques, high current pulsed electron beam (HCPEB) is relatively new $[5,6]$. Under the action of HCPEB, a high energy $\left(10^{8}-10^{9} \mathrm{~W} / \mathrm{cm}^{2}\right)$ is deposited only in a very thin layer (less than tens of micrometers) within a short time (a few microseconds), which can

*Corresponding author: Jie Cai, Institute of Advanced Manufacturing and Modern Equipment Technology, Jiangsu University, Zhenjiang, China; School of Mechanical Engineering, Jiangsu University, Zhenjiang, China, E-mail: caijie@ujs.edu.cn

Qingfeng Guan, Peng Lv, Conglin Zhang, School of Materials Science and Engineering, Jiangsu University, Zhenjiang, China Yunxiao Yin, School of Energy and Power Engineering, Jiangsu University, Zhenjiang, China produce extremely fast heating and cooling of the surface and thermal stress. As a result, abundant metastable microstructures or phase structures, such as supersaturated solid solution [7], ultra-fine grains [8] and nanostructures $[8,9]$ are formed on the irradiated surfaces, which can ultimately influence their physicalmechanical properties. Unfortunately, one of the major negative effects is the crater formation on the surface, which is commonly regarded as a deterioration of the mechanical reliability in structural materials and limits the application of this new technique [10-13]. In a recent paper, Proskurovsky et al. [13] indicated that the crater formation can lead to an increase in surface roughness and highly nonuniform strain-stress states of local regions. These changes impaired the strength and corrosion resistance of the material. Therefore, the mechanisms of the crater formation have been studied in detail in order to control the formation of crater and eliminate its negative effect.

Actually, several mechanisms have been proposed to explain the formation of craters, which have considerable differences in appearance of various materials after HCPEB irradiation. Pogrebnjak et al. [14] investigated the near-surface of pure iron by using a combination of several different techniques and demonstrated that the high density of nonequilibrium vacancy defects offered the favorable sites for crater nucleation. Zhang et al. [15] explored the pitting corrosion behaviors of AlSI 316L stainless steel irradiated by HCPEB, recommending that the second phase particles can be served as nucleation sites for the formation of subsurface melting pools. Qin et al. [16] made an in-depth analysis of the initial melting positions, crater depths and melting layer thickness by simulating the melting process and their temperature profiles for substrates of aluminum and steels based on experimental investigations and a physical model. They proposed that a subsurface layer heating and melting can cause the eruptions of liquid metals in the subsurface layer through the outermost surface and produce typical craters. Existing studies are virtually devoted to the process and mechanism of the craters when they are formed. However, detail 
information about the phenomenon that the craters fail to be formed (i.e. "crater free" phenomenon) after HCPEB irradiation is still missing. In our experiments, we unexpectedly found that the craters failed to be formed of pure zirconium during the electron beam processing, which plays a dominant role in HCPEB modification of zirconium and zirconium alloys. Consequently, there is a need to examine the mechanism of the "crater-free" phenomenon, which constitutes the subject of this article.

The discussion was developed based on two targets both of 3Cr13 stainless steel and pure zirconium. We will point out the different mechanisms of the crater occurrence and absence in different materials, and gain more insights into the factors that determine their formation, in order to supply the necessary theoretical foundation and experimental preparation for surface modification of zirconium and zirconium alloys by HCPEB technique.

\section{Experimental Section}

Samples of $3 \mathrm{Cr} 13$ stainless steel and pure about 99\% zirconium were used for investigation in this work. Corresponding chemical composition of $3 \mathrm{Cr} 13$ stainless steel was listed in Table 1 . The specimens were machined to dimension of $10 \mathrm{~mm} \times 10 \mathrm{~mm} \times 10 \mathrm{~mm}$, and one side of the sample was mirror polished to ensure a similar surface state. The polished surfaces were irradiated at room temperature by using a Nadezhda-2 type HCPEB source with 1, 5, 10 and 20 pulses, respectively. The HCPEB irradiation was carried out under the following conditions: the electron energy $27 \mathrm{KeV}$, the current pulse duration $1.5 \mu \mathrm{s}$, the energy density about $4 \mathrm{~J} \cdot \mathrm{cm}^{-2}$, and vacuum $10^{-5}$ Torr. More details of the principle about this type of HCPEB facility are reported in reference [17].

Table 1: Chemical composition of $3 \mathrm{Cr} 13$ stainless steel.

\begin{tabular}{lrrrrrrrr}
\hline Element & $\mathbf{C}$ & $\mathbf{C r}$ & $\mathbf{M n}$ & $\mathbf{S}$ & $\mathbf{P}$ & $\mathbf{N i}$ & $\mathbf{S i}$ & $\mathbf{F e}$ \\
\hline Wt./\% & 0.28 & 13.26 & 0.58 & 0.015 & 0.018 & 0.50 & 0.82 & Bal.
\end{tabular}

Microstructural examinations were performed with an optical microscopy (OM) of type LEICA DM22500M, a scanning electron microscopy (SEM) of type JSM-7001F and surface profiler of type NT1100 (for detecting the surface roughness).

\section{Results}

\section{$3 c r 13$ stainless steel}

Figure 1 gives typical surface morphologies of $3 \mathrm{Cr} 13$ stainless steel irradiated by 5, 10 and 20 pulses. It is clearly that the craters were homogeneously distributed on the entire surface, and their density was decreased obviously with the increment of HCPEB pulses. As seen from Figure 1(a) and (b), some craters were isolated and fairly far away from one another and adopted a regular rounded shape with relatively small size of $50 \mu \mathrm{m}$. However, their shape was more complicated when they impinged on each other, which presented a much larger size. Interestingly, seen from Figure 1(c), the shape and size of the craters were very different after 20 -irradiated pulses. These craters possessed wavy feature with obscure edges, which looked like small "worms". Though the crater density was very different with the various pulses, the roughness of irradiated surfaces was all very high. Figure 1(d) shows the three-dimensional surface micrograph of 20-pulsed sample measured by using a surface profiler technique. It can be noticed clearly that the surface presented undulating morphology with high roughness. Roughness ( $\mathrm{Ra}$ ) measurement on the irradiated surface was performed. The value of that was $1.915 \mu \mathrm{m}$ of 20 pulsed sample, which was perceptibly increased compared to the initial one. It was attributed to the emergence of surface irregularity after forming abundant craters by HCPEB irradiation. According to the Qin et al. [16] suggestion, such typical morphologies were the consequence of local sub-layer melting and eruption through the solid outer surface.

\section{Pure zirconium}

Figure 2 illustrates the irradiated surface morphologies of pure zirconium at low magnification with $1,5,10$ and 20 HCPEB pulses. As indicated in Figure 2(a), few volcano-like craters appeared on the irradiated surface after 1-pulsed irradiation, demonstrating that locally melting occurred on the surface during HCPEB irradiation. However, interesting and somehow surprising result revealed in Figure 2(b)-(d) is the absence of craters after multi-pulses, and simultaneously, homogeneous microstructure is remarkable. Figure 2(e) shows the three-dimensional surface micrograph of pure zirconium with 20-pulsed irradiation, which shows an extremely smooth surface. Some results of the 

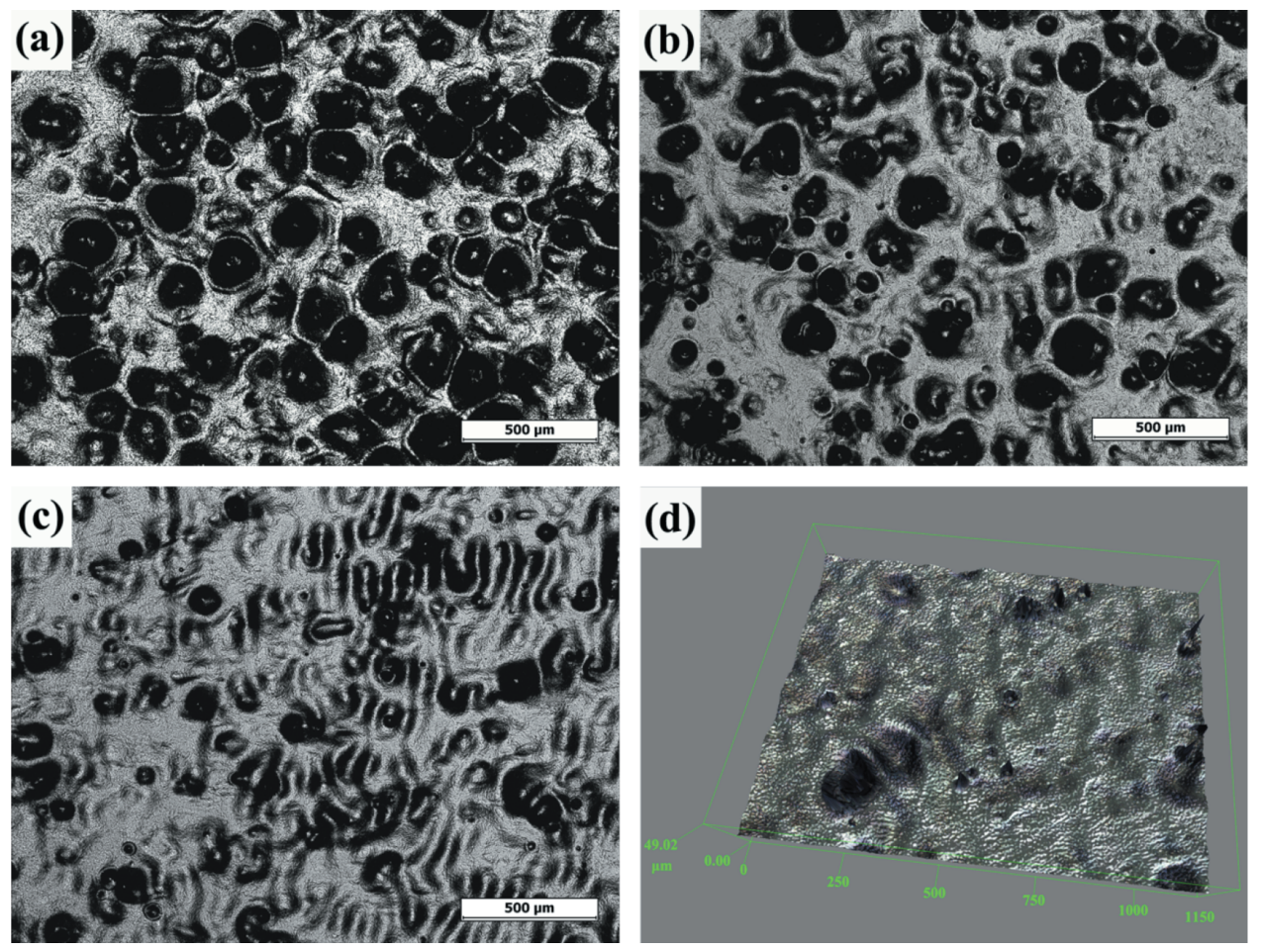

Figure 1: Typical surface micrographs of HCPEB-treated $3 \mathrm{Cr} 13$ stainless steel samples: (a) OM, 5 pulses, (b) OM, 10 pulses, (c) OM, 20 pulses, (d) laser threedimensional image, 20 pulses.

roughness (Ra) of the experiments are present in Table 2 . One more important consequence is the relatively low value of $\mathrm{Ra}$ of pure zirconium. It reached to a maximal value of $0.242 \mu \mathrm{m}$ with the first irradiated pulse, and then decreased continuously with the subsequent pulses, and finally reduced to a final $\mathrm{Ra}$ of $0.128 \mu \mathrm{m}$ at 20 pulses. Compared to the value of $3 \mathrm{Cr} 13$ stainless steel, the surfaces of the irradiated samples of pure zirconium are much more smoothing.

Figure 3 presents the magnified surface morphologies of the regions where the craters were formed after HCPEB irradiation. After 5-pulsed irradiation (Figure 3 (a)), the crater had a deep center-dimpling shape with a small bottom hole and was abounded by multiple wrinkled loops. It approved that such morphology was the result of local subsurface layer melting and eruption through the solid outer surface. The formation of such a crater still obeyed to the eruption mechanism presented by Qin et al. [16] However, it is evident that the size of the crater reached even $480 \mu \mathrm{m}$, which was considerably larger than that of any other metallic materials (several tens microns). The other magnified surface morphology of 10-pulsed sample is shown in Figure 3(b). The region marked by an arrow displays the recognizable trace of surface melting, but the typical eruptive structures failed to be formed. Besides, a crack can be clearly observed in the center of the individual crater, which remained a main cause of eruptive failure.

It's worth noting that ultrafine grains were formed on the remelted surface after HCPEB irradiation. Figure 4 reveals the SEM images of the regions where the craters were seldom observed with 1, 5, 10 and 20 pulses, respectively. The size of ultrafine grains directly evaluated from Figure 4, was $1 \sim 2 \mu \mathrm{m}$, approximately. After 20-pulsed irradiation, abundant ultrafine grains can be found due to the surface was remelted more thoroughly. During the transient HCPEB irradiation process, a high energy was deposited and caused superfast heating and melting of the surface. Subsequently, superfast solidification and cooling process introduced the formation of large numbers of the nucleuses, whereas there was not enough time for them to grow up. Consequently, ultrafine grains were formed on the irradiated surface, which clearly indicated that the surface layer was completely melted.

\section{Discussions}

\section{3 cr13 stainless steel}

Seen from Figures 1 and 2, the shape, density and size of craters are diverse in terms of different materials under 

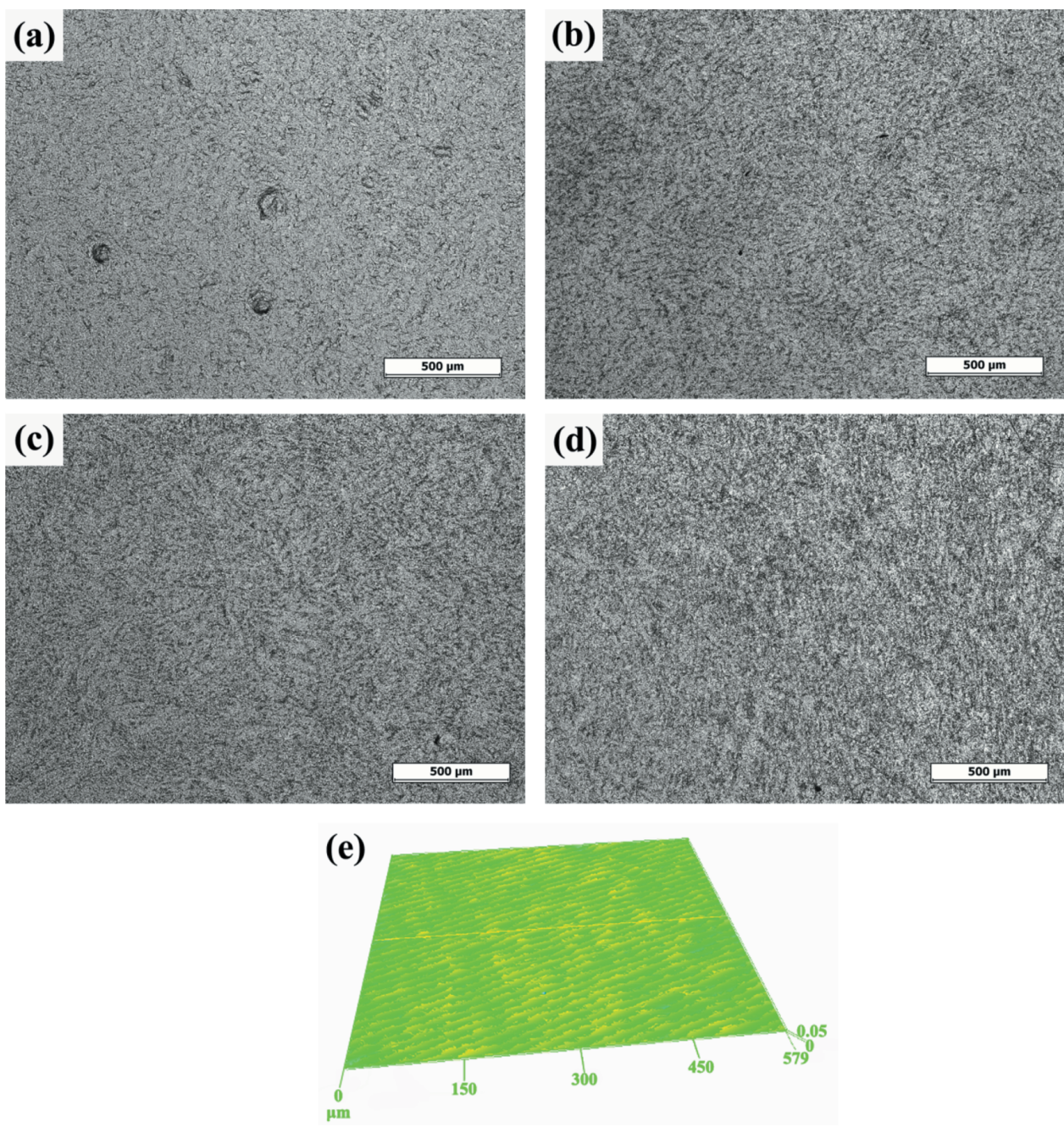

Figure 2: Optical micrographs taken on the HCPEB-treated pure zirconium with (a) 1 , (b) 5 , (10), and (d) 20 pulses, respectively.

Table 2: Surface roughness of materials with different pulses.

\begin{tabular}{lrr}
\hline Samples & HCPEB Pulses & Ra $(\mu \mathrm{m})$ \\
\hline Pure zirconium & 1 & 0.242 \\
& 5 & 0.222 \\
& 10 & 0.168 \\
3Cr13 stainless steel & 20 & 0.128 \\
\hline
\end{tabular}

the same HCPEB irradiated conditions. Crater formation shown in Figure 1 is the most common phenomenon, of which the reasonable mechanism can be interpreted by local sublayer melting and eruption $[15,16,18]$.

During HCPEB irradiation, a local melting started at the subsurface layer, resulting in the nucleation of small melting pools, as illustrated in Figure 5(a). Each melting pool was confined with the surrounding solid. Subsequently, the volume expansion occurred due to the transformation from the solid to the liquid. During this process, an expansion force was exerted on the droplets and was transmitted by the droplets in all direction. The expansion force was then enhanced by the temperature increasing and converted to a significant counter force to the top surface (Figure 5(b)). As counter force increased and molten droplet grew, the liquid melts would diffuse to the surface with high liquid pressure. If the outer thin solid layer cannot withstand this pressure, a volcano-like eruption would occur, as show in Figure 5(c), which is just like the craters in Figure 1. Such kind of crater formation has been observed on pure metals and carbon steels irradiated by HCPEB treatment $[5,9,19]$. After multi-pulsed irradiation, the craters formed previously were likely to be fused or removed by the subsequent pulses (Figure 1 (c)). Nevertheless, with regard to the absence of the craters of pure zirconium, the above mechanism is not absolutely valid. 

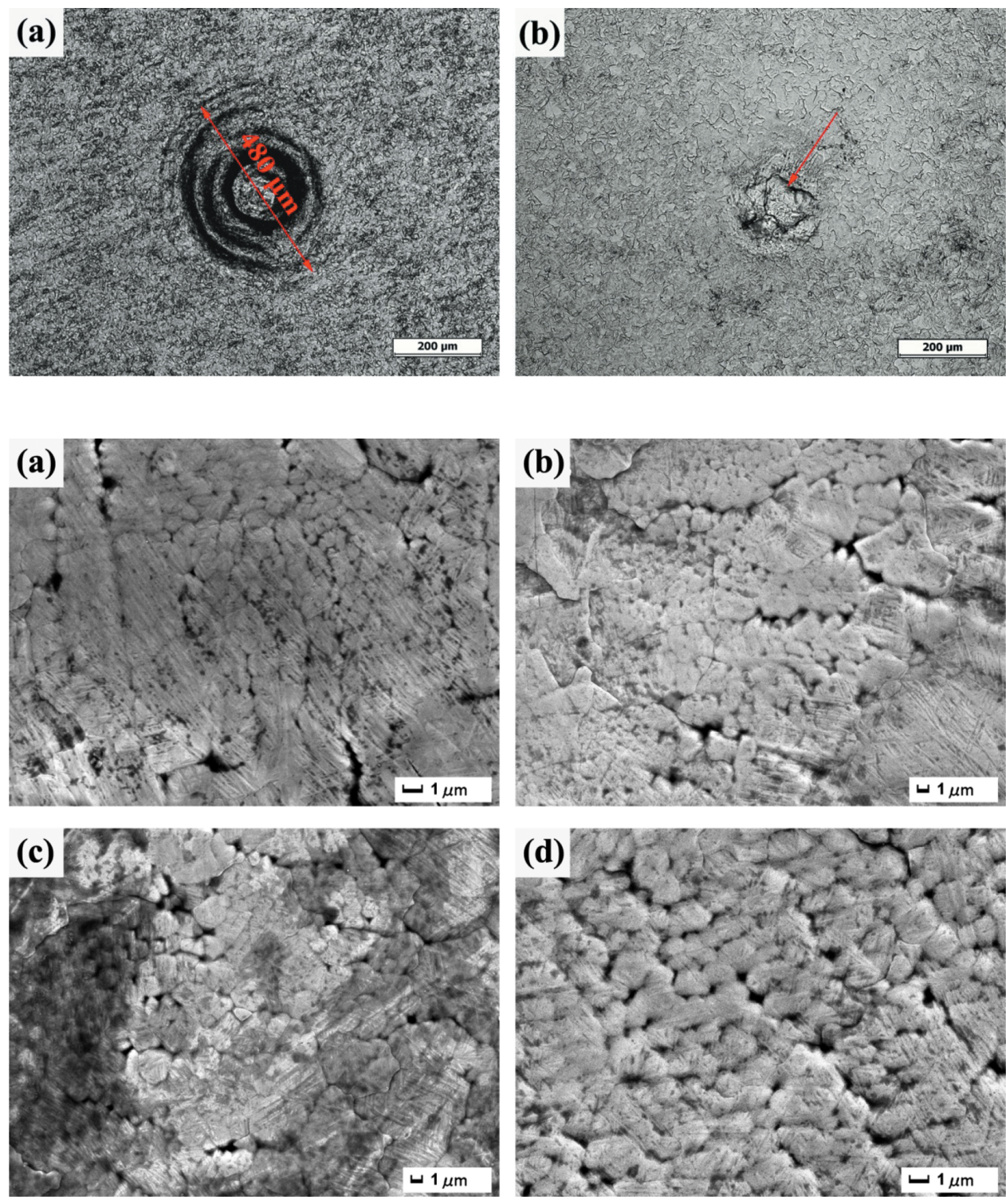

Figure 3: High magnifications of craters on the surface of pure zirconium with: (a) 5 pulses and (b) 10 pulses.
Figure 4: Ultrafine grains on the surface of pure zirconium treated with (a) 1, (b) 5, (c) 10 and (d) 20 pulses, respectively.
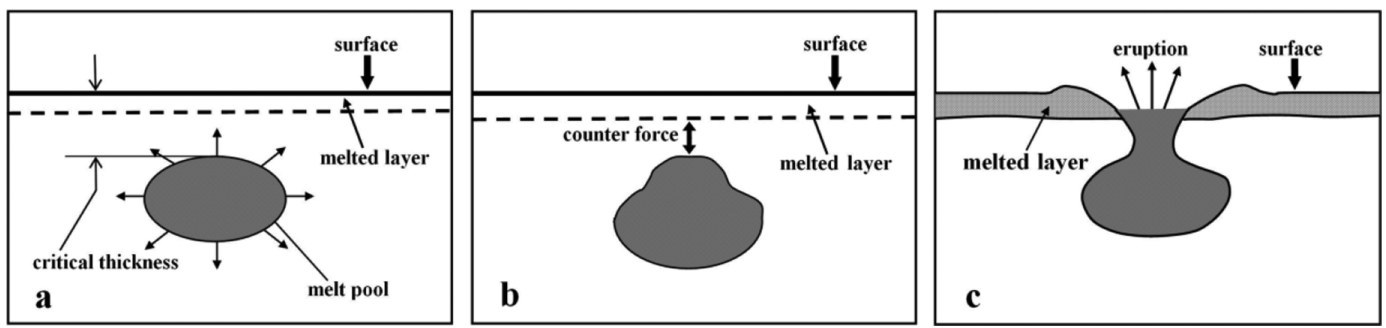

Figure 5: Schematic illustration of craters that succeeded to be erupted of $3 \mathrm{Cr} 13$ stainless steel.

\section{Pure zirconium}

Among the works dealing with craters induced by HCPEB irradiation, we noticed in particular the work done by Qin [16] who discussed the nucleation sites of craters using a combination method of experimental investigation and numerical simulation. They discovered that the starting melting site, the maximum depth of craters and the maximum melting depth were sensitive to material properties due to the difference in thermal conductivity and electron 
penetration range. Comparing Figures 1 and 2, which were derived from the different materials but with the same irradiation condition, the atomic number of $\operatorname{Zr}(40)$ is larger than that of $\mathrm{Fe}$, which results in smaller electron penetration range. For thermal conductivity, it is roughly equal to that of carbon steel $\left(1.4 \times 10^{-4} \mathrm{~m}^{2} \mathrm{~s}^{-1}\right)$ for $\operatorname{Zr}\left(1.2 \times 10^{-4} \mathrm{~m}^{2} \mathrm{~s}^{-1}\right)$. Therefore its melting site is rather less than that of carbon steel (about $0.22 \mu \mathrm{m}$ from the surface). That is, after HCPEB irradiation the melting pools of pure zirconium were located at a very shallow depth from the outmost surface (shown in Figure 6(a)). Typically each pool of the melt was surrounded by the ambient matrix. Under the action of the electron beam and further heating, these melting pools grew in size, and simultaneously the internal ejection pressure was generated due to thermal expansion and volume change. The pressure can make the pools burst through the thin solid wall from the upper melted surface. Such kind of crater formation can be observed in Figure 3(a). However, it is somehow surprising that the size of crater was certainly larger in comparison with any other metallic materials (several tens microns). This was primarily due to the fact that the started melting site in zirconium was too shallow, and the thickness of the solid layer was extremely thin. Although the irradiated surface of pure zirconium has been polished, it was hard to obtain absolutely ideal mirror surface. Thus the thin solid layer between melting pools and treated surfaces probably has been in an incomplete state. At this stage, the expansion of melting pools failed to erupt normally due to the broken outer solid layer. The melting pool has lost the constraint of surrounding matrix (shown in Figure 6(b)), but continued to melt on the surface (Figure 6(c)). The observation of a melted morphology in Figure 3(b) is consistent with this proposed mechanism. Moreover, abundant deformation structures such as slip band, shear band, micropores were generated under the high-amplitude stress after HCPEB irradiation, which are related to the surface integrity [19].

Figure 7 reveals the intense and complex plastic deformations induced on the irradiated surface with 1 HCPEB pulse. Figure 7(a) is showing the micropores,
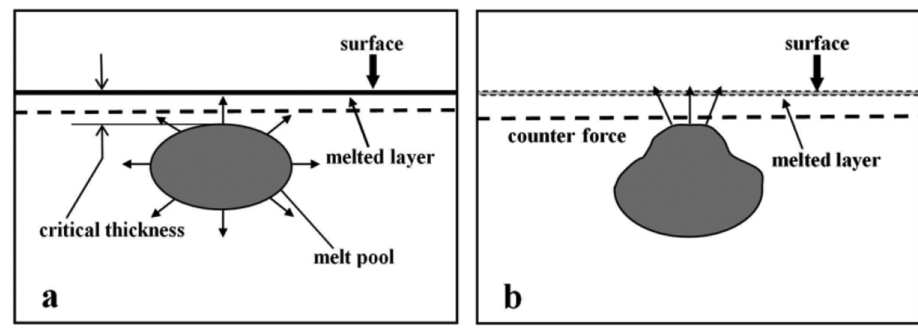

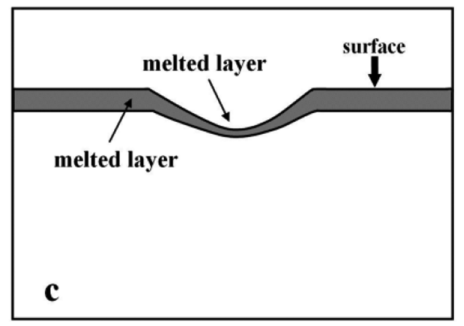

Figure 6: Schematic illustration of crater that failed to be erupted of pure zirconium.
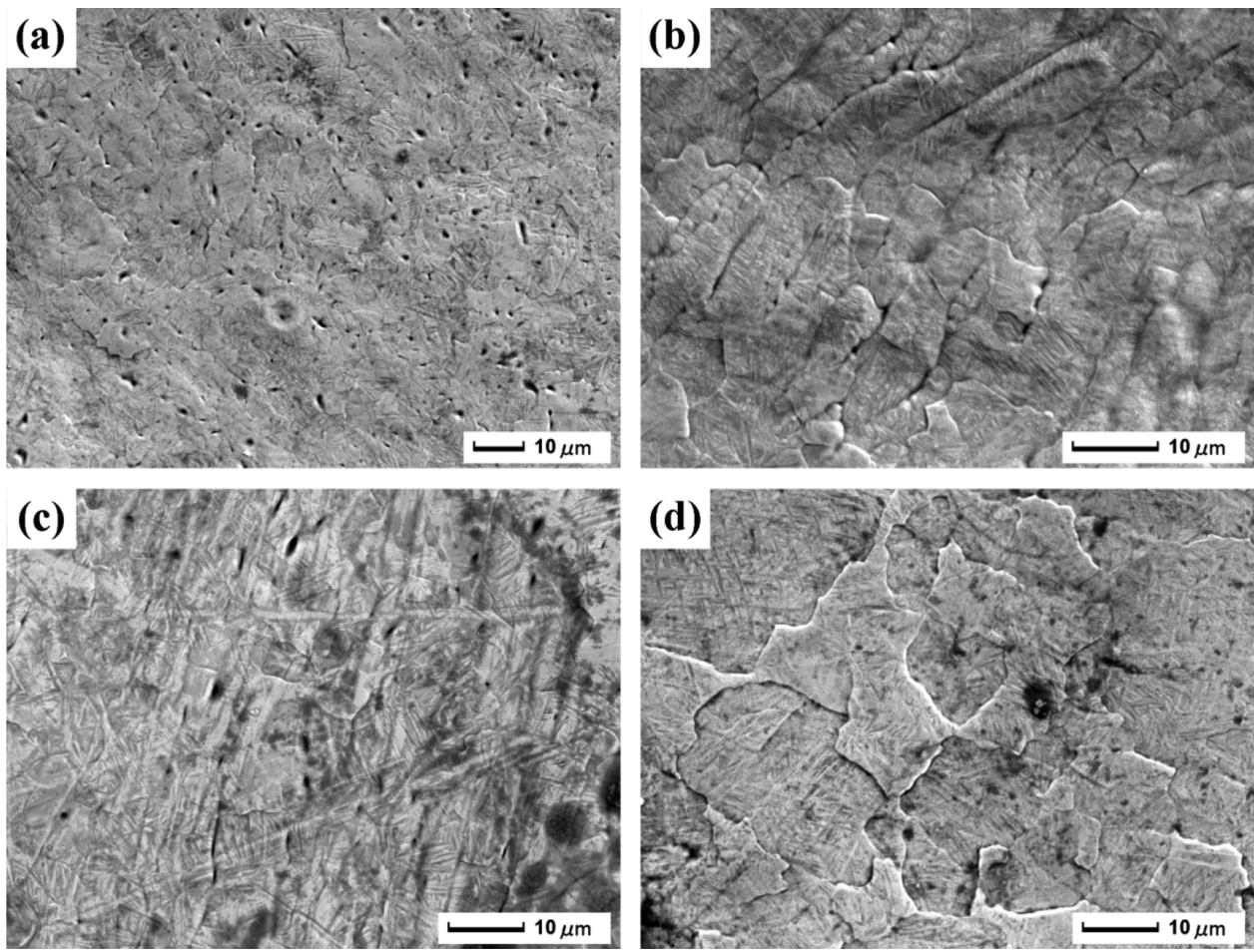

Figure 7: Deformation structures induced by HCPEB irradiation of pure zirconium (a) micropores, (b) elongated grain structures, (c) shear band and (d) grains with different crystal orientations. 
which were isolated from each other. These microspores were formed during HCPEB irradiation duo to the rapid cooling process. The surface started superfast cooling once the beam pulse ended, and simultaneously, severe tension stress resulted in fast contraction, and then the pores were frozen during re-solidification. Figure $7(\mathrm{~b})$ shows the elongated grain structures, and each of them contained dense slipping lines that were paralleled to one another. Figure 7(c) represents the shear bands. It is worth noting that these shear bands can pass through several grains, whereas the slip bands were limited in one grain. Shear localization is an important deformation and often a dominating failure mechanism at high strain rates subjected to impact load, such as high-speed impact, punching and high speed molding [20]. The formation of shear band is regarded as a premonition of material instability, which means load bearing capacities of materials are decreased. Another representative feature is shown in Figure 7(d). It can be clearly seen that the irradiated region was no longer smooth, and different grain surface presented the different crystal orientations, which can be distinguished evidently by the separate grains. It is believed that this structure was the result of grain rotation in order to keep deformation compatibility in grain deformation process induced by high-amplitude thermal stress during HCPEB irradiation [21, 22].

From above microscopic perspectives, it can be considered that HCPEB irradiation can cause intense deformation and lead to the deformation structures on the surface of pure zirconium. This could be regarded as the deterioration of surface integrity, as well as the thin solid layer. Thus, the erupted chances of the craters could reduce significantly. Under this circumstance, surface melting was the dominant interaction mechanism between HCPEB irradiation and pure zirconium, with the consequence of producing ultrafine grains. Due to this "crater-free" surface, a desirable value of roughness (Ra) can be achieved (given in Table 2), which played a significant role in corrosion resistance of pure zirconium. As we know, during the process of electrochemical corrosion, crater regions can damage the formation of a thick and dense passive surface layer, and turn into sensitive sites for very effective pitting corrosion [23, 24]. In a recent review paper, Proskurovsky et al. [13] indicated that the craters could cause an increase of surface roughness and highly non-uniform strain-stress states in the near-surface layer of local regions. These changes should impair the strength and corrosion-resistance properties of the material. However, in our study, microstructural observations demonstrate that almost no craters were formed on the surface of pure zirconium, which is evidently distinct from the case of other metal materials, like 3Cr13 stainless steel irradiated by HCPEB. Therefore, the pure zirconium after HCPEB irradiation would have excellent corrosion resistance. The present results provide a potential approach to surface modification of zirconium and/or zirconium alloys with promising development potential.

\section{Conclusions}

In conclusion, the experimental results show the possibility of "crater-free" surface of pure zirconium expected by using HCPEB technique. The formation of craters of stainless steel $3 \mathrm{Cr} 13$ was the result of local sublayer melting and eruption through the solid outer surface. Comparatively, almost no craters were created on the surface of pure zirconium irradiated by HCPEB, which was associated with the shallow melting site and incomplete treated surface. Craters failed to be erupted normally because they had lost the constraint of surrounding matrix. Besides, ultrafine grains were formed on the irradiated surface, indicating that surface melting was the dominant interaction mechanism between HCPEB irradiation and pure zirconium.

Acknowledgments: Financial supports from the National Natural Science Foundation of China (No 51601072), the Natural Science Foundation of Jiangsu Province for Youths (No. BK20160530), the China Postdoctoral Science Foundation (No. 2016M601730), the Postdoctoral Foundation of Jiangsu Province (No. 1601007C), and Youth Talent Development Program of Jiangsu University are acknowledged.

Funding: This work was supported by the National Natural Science Foundation of China; [51601072]; Natural Science Foundation of Jiangsu Province for Youths; [BK20160530]; China Postdoctoral Science Foundation; [2016M601730]; Postdoctoral Foundation of Jiangsu Province; [1601007C]; Youth Talent Development Program of Jiangsu University.

\section{References}

[1] A.D. Pogrebnjak, V.S. Ladysev, N.A. Pogrebnjak, A.D. Michaliov, V.T. Shablya, A.N. Valyaev, A.A. Valyaev and V.B. Loboda, Vacuum, 58 (2000) 45-52. 
[2] J. Cai, S.Z. Yang, X.T. Wang, Y. Li, X.L. Hou and Q.F. Guan, Chin. Sci. Bull., 58 (2013) 2507-2511.

[3] J. Cai, P. Lv, Q.F. Guan, X.J. Xu, J.Z. Lu, Z.P. Wang and Z.Y. Han, ACS Mater. Inter., 8 (2016) 32541-32556.

[4] J.Z. Lu, L.J. Wu, G.F. Sun, K.Y. Luo, Y.K. Zhang, J. Cai, C.Y. Cui and X.M. Luo, Acta Mater., 127 (2017) 252-266.

[5] Y. Qin, C. Dong, Z.F. Song, S.Z. Hao, X.X. Mei, J.G. Li, X.G. Wang, J.X. Zou and T. Grosdidier, J. Vac. Sci. Technol. A, 27 (2009) 430-435.

[6] J. Cai, Q.F. Guan, X.L. Hou, Z.P. Wang, J.X. Su and Z.Y. Han, Appl. Surf. Sci., 317 (2014) 360-369.

[7] Z.Y. Han, L. Ji, J. Cai, H. Zou, Z.P. Wang and Q.F. Guan, J. Nanomater., 603586 (2013) 603586.

[8] J. Cai, S.Z. Yang, L. Ji, Q.F. Guan, Z.P. Wang and Z.Y. Han, Surf. Coat. Technol., 251 (2014) 217-225.

[9] Q.F. Guan, P.L. Yang, H. Zou and G.T. Zou, J. Mater. Sci., 41 (2006) 479-483.

[10] V.A. Shulov, N.A. Nochovnaia and G.E. Remner, Surf. Coat. Technol., 158 (2002) 488-493.

[11] K.M. Zhang, J.X. Zou, T. Grosdidier and C. Dong, Vacuum, 86 (2012) 1273-1277.

[12] V.A. Shulov and N.A. Nochovnaya, Nucl. Instrum. Methods. Phys. Res., 148 (1999) 154-158.

[13] D.I. Proskurovsky, V.P. Rotshtein, G.E. Ozur, Y.F. Ivanov and A.B. Markov, Surf. Coat. Technol., 125 (2000) 49-56.
[14] A.D. Pogrebnjak, A.D. Mikhaliov, N.A. Pogrebnjak, Jr, Y.V. Tsvintarnaya, V.I. Lavrentiev, M. Iljashenko, A.N. Valyaev, S. Bratushka, A. Zecca and R. Sandrik, Phys. Lett. A, 241 (1998) 357-363.

[15] K.M. Zhang, J.X. Zou, T. Grosdidier, C. Dong and D.Z. Yang, Surf. Coat. Technol., 201 (2006) 1393-1400.

[16] Y. Qin, C. Dong, X.G. Wang, S.Z. Hao, A.M. Wu, J.X. Zou and Y. Liu, J. Vac. Sci. Technol. A, 21 (2003) 1934-1938.

[17] C. Dong, A.M. Wu, S.Z. Hao, J.X. Zou, Z.M. Liu, P. Zhong, A.M. Zhang, T. Xu, J.M. Chen, J. Xu, Q. Liu and Z.R. Zhou, Surf. Coat. Technol., 163-164 (2003) 620-624.

[18] Q.F. Guan, X.T. Wang, J. Zhu, K.M. Chen, L. Liang, Q.Y. Zhang and C. Dong, ISIJ Int., 49 (2009) 1449-1451.

[19] S.Z. Hao, B. Gao, A.M. Wu, J.X. Zou, Y. Qin, C. Dong, J. An and Q.F. Guan, Nucl. Instrum. Methods Phys. Res. B, 240 (2015) 646-652.

[20] Q. Xue, M.A. Meyers and V.F. Nesterenko, Acta Mater., 50 (2002) 575-596.

[21] A. Thompson and A. Strachan, Phys. Rev. B, 81 (2010) 085429.

[22] S.K. Mishra, S.M. Tiwari, A.M. Kumar and L.G. Hector, Metall. Mater. Trans. A, 43 (2012) 1598-1609.

[23] J.X. Zou, K.M. Zhang, S.Z. Hao, C. Dong and T. Grosdidier, Thin Solid Films, 519 (2010) 1404-1415.

[24] J.X. Zou, K.M. Zhang, C. Dong and Y. Qin, Appl. Phys. Lett., 89 (2006) 041913. 